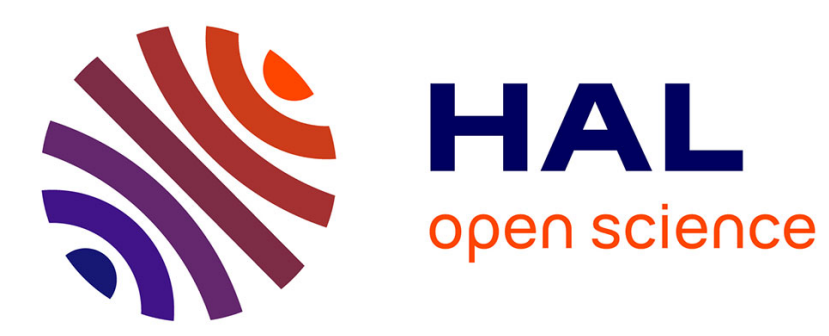

\title{
Economic Activity and Recession Probabilities: information content and predictive power of the term spread in Italy
}

Costanza Torricelli, Marianna Brunetti

\section{- To cite this version:}

Costanza Torricelli, Marianna Brunetti. Economic Activity and Recession Probabilities: information content and predictive power of the term spread in Italy. Applied Economics, 2009, 41 (18), pp.23092322. 10.1080/00036840701222512 . hal-00582090

\section{HAL Id: hal-00582090 \\ https://hal.science/hal-00582090}

Submitted on 1 Apr 2011

HAL is a multi-disciplinary open access archive for the deposit and dissemination of scientific research documents, whether they are published or not. The documents may come from teaching and research institutions in France or abroad, or from public or private research centers.
L'archive ouverte pluridisciplinaire HAL, est destinée au dépôt et à la diffusion de documents scientifiques de niveau recherche, publiés ou non, émanant des établissements d'enseignement et de recherche français ou étrangers, des laboratoires publics ou privés. 


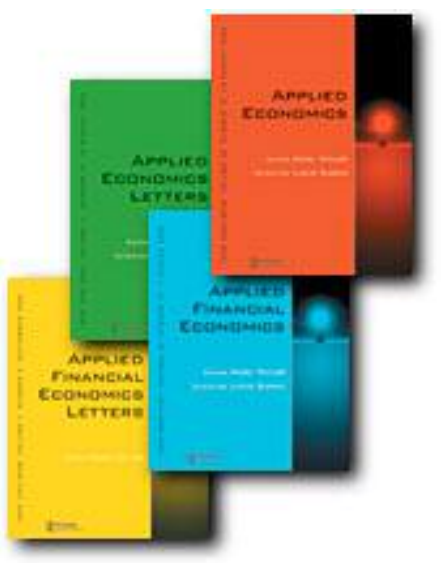

Economic Activity and Recession Probabilities: information content and predictive power of the term spread in Italy

\begin{tabular}{|c|l|}
\hline Journal: & Applied Economics \\
\hline Manuscript ID: & APE-06-0155.R1 \\
\hline Journal Selection: & Applied Economics \\
\hline JEL Code: & $\begin{array}{l}\text { C50 - General < C5 - Econometric Modeling < C - Mathematical and } \\
\text { Quantitative Methods, E43 - Determination of Interest Rates } \mid \text { Term } \\
\text { Structure of Interest Rates < E4 - Money and Interest Rates < E - } \\
\text { Fluctuations |Cycles < E3 - Prices, Business Fluctuations, and Cycles } \\
<\text { E - Macroeconomics and Monetary Economics }\end{array}$ \\
\hline Keywords: & economic activity, term spread, business cycle, regime prediction \\
\hline
\end{tabular}

\section{S ScholarONE" \\ Manuscript Central}




\title{
Economic activity and recession probabilities:
} information content and predictive power of the term spread in Italy

\author{
Marianna Brunetti, University of Modena and Reggio Emilia and CEFIN \\ Costanza Torricelli, University of Modena and Reggio Emilia and CEFIN*
}

\begin{abstract}
The aim of the present paper is to examine the information content of the Italian term spread as for real economic growth rates and recession probabilities and to test its predictive power in forecasting regime probabilities. To this end the relationship between the term spread and economic growth rates is modelled as a nonlinear one and specifically the Logistic Smooth Transition model is used, while a probit model is implemented to forecast recession probabilities. Specific to this paper is the use of the OECD business cycle chronology, which was never used before to this end for the Italian case. Overall evidence supports the informative content of the spread in Italy over the whole period (1984-2005) although results are more satisfactory as from 1992. In particular, recession forecasts are generally better than those obtained with other chronologies previously adopted for the Italian case (ISAE and ECRI).
\end{abstract}

December 2006

Keywords : economic activity, term spread, business cycle, regime prediction JEL Classification: E32, E43, C50

\footnotetext{
*Corresponding author: Costanza Torricelli, Dipartimento di Economia Politica, Viale Berengario 51, 41100 Modena, Italy, Tel. +39 0592056733 Fax +39 059 2056937, e-mail:torricelli.costanza@unimore.it
} 


\title{
Economic activity and recession probabilities:
}

information content and predictive power of the term spread in Italy

\begin{abstract}
The aim of the present paper is to examine the information content of the Italian term spread as for real economic growth rates and recession probabilities and to test its predictive power in forecasting regime probabilities. To this end the relationship between the term spread and economic growth rates is modelled as a nonlinear one and specifically the Logistic Smooth Transition model is used, while a probit model is implemented to forecast recession probabilities. Specific to this paper is the use of the OECD business cycle chronology, which was never used before to this end for the Italian case. Overall evidence supports the informative content of the spread in Italy over the whole period (1984-2005) although results are more satisfactory as from 1992. In particular, recession forecasts are generally better than those obtained with other chronologies previously adopted for the Italian case (ISAE and ECRI).
\end{abstract}

Keywords : economic activity, term spread, business cycle, regime prediction JEL Classification: E32, E43, C50 


\section{Introduction}

Information about the future economic performance of a country is of uttermost importance in a number of applications. Policy makers need forecasts on future economic growth rates in order to design the correct stance of their policies. In finance, a new field of application is represented by the international accord known as Basel II, which sets, within a broader regulatory framework, new and more risk-sensitive capital requirements that naturally depend on the state of the economy. ${ }^{1}$

The Term Structure of Interest Rates (TSIR) and in particular the term spread, i.e. the difference between a long- and a short-term interest rate, is taken in the literature as an indicator of market expectations about future economic performances (e.g. Estrella and Hardouvelis (1991), Estrella and Mishkin (1997, 1998), Bernard and Gerlach (1998), Ang et al., 2006). It is particularly attractive for this purpose as TSIR data are instantaneously available also for long maturities, so that forecasts are possible over long horizons as well. The predictive power of the term spread about future economic performances basically stems from the Rational Expectation Hypothesis (EH), according to which long-term interest rates are averages of appropriate expected future shortterm interest rates. In particular, when the market anticipates a recession, a reduction in expected future short-term interest rates is anticipated and the TSIR flattens, so that a change in the slope of TSIR (i.e. in the term spread) indicates a change in the expected future economic performances. This basic EH connection between the term spread and future real activity may be modified via two main channels: monetary policy and intertemporal consumers choices. Consider a tightening monetary policy: short-term interest rates rise, whereas long-term rates also rise but generally less than the former, leading to a reduction of the term spread. The contraction can induce lower spending in sensitive sectors of the economy and thus a slowdown in the economic growth rates (see Estrella (2005) for a comprehensive theoretical rational expectations model and Estrella and Mishkin (1997) for empirical evidence in favour of the key role played by the monetary policy in the relationship between the TSIR and future real output). On the other hand, intertemporal

\footnotetext{
${ }^{1}$ For example, in Pederzoli and Torricelli (2005) regime predictions are used to estimate default probabilities and then, based on a forward-looking approach, capital requirements are calculated within the Basel II framework.
} 
consumer choice theory assumes that consumers prefer stable rather than fluctuating levels of income. Accordingly, if a recession is expected consumers will increase savings and buy long-term bonds to get payoffs during the slowdown, inducing a decrease of long-term yields. On the other hand, they may sell short-term bonds making the relative yields rise. Therefore, when a recession is expected, the term spread reduces and the TSIR flattens (see e.g. Harvey (1988) for a full account). Many empirical works in literature have investigated the spread as a predictor of future economic activity but only a few have analysed this issue for the Italian case: e.g. Estrella and Mishkin (1997) and Sensier et al. (2004) perform comparative studies, Moneta (2003) tests the consistency between Euro area and individual countries, Marotta et al. (2006) focus on the case of Italy and forecast recession likelihood in order to estimate default probabilities.

The aim of the present paper is to examine the information content of the Italian term spread as for real economic growth rates and recession probabilities and to test its predictive power in forecasting regime probabilities. The present analysis differs from previous works on the Italian case for the following features. First, two approaches are implemented in order to test the robustness of the informative content of the term spread. In the former, the term spread is used as explanatory variable of future growth rates of the real economy and specifically a nonlinear model is implemented, namely the Logistic Smooth Transition (LSTR) model. In the latter, the spread is used to predict the likelihood of future recessions and a binary probit model is employed for the prediction of recession probabilities. Second, a more recent and a higher-frequency dataset is used. More precisely, monthly rather than quarterly data are used, so that a closer match between the business cycle chronology and the classification of recession/expansion periods in the sample under analysis is possible. Finally, in order to assess the sensitivity of the results to the business cycle chronology used, this paper departs from Marotta et al. (2006) by considering the OECD chronology.

The remainder of the paper is organized as follows. Section 2 briefly reviews the literature on the predictive power of the term spread over economic growth rates and regime probabilities. Section 3 
illustrates the econometric framework used to test the information content and the predictive power of the spread. Section 4 describes the dataset, the empirical analyses and discusses the results obtained. Section 5 presents the forecast analysis and Section 6 compares results with literature. Last Section concludes.

\section{Literature Overview}

The literature on the term spread as an indicator of market expectations about future economic performances is extremely vast. In this Section we focus on the studies taking the terms spread as predictor of either real output or recession probabilities.

Earlier works on the predictive content of the term spread for real output rest on simple linear models. ${ }^{2}$ Among others, Harvey (1989) reports that US real GNP growth rates 1- to 5-quarter ahead significantly depend on the contemporaneous values of the spread between 5-year T-Bond and 3month T-Bill rates. Similarly, Estrella and Hardouvelis (1991) using US quarterly data observe that the slope of the TSIR measured by the spread between 10-year T-Bond and 3-month T-Bill rates predicts quite well both cumulative changes in real GNP and recession probabilities up to four years ahead. However, empirical evidence on the informative power of the spread is not always consistent between countries: Plosser and Rouwenhorst (1994) for instance confirm the predictive power of the spread for US, Canada and Germany, but not for France and UK.

By contrast, more recent works implement nonlinear models. More specifically, the nonlinearities typical of the relationship between a term spread and real economic growth have been generally modelled by means of either threshold models or Markov Switching models. Among the studies adopting the latter approach, Artis et al. (2004) employ Markov Switching auto-regressions to model the growth rates of nine European countries (Austria, Belgium, France, Germany, Italy, Netherlands, Spain, Portugal and UK) with the final aim to detect a common European growth cycle. Also Korenok et al. (2004) present nonparametric evidence based on a Markov-switching

\footnotetext{
${ }^{2}$ See e.g. Stock and Watson (2003) for an extensive survey of this literature.
} 
framework and find that term spread and consumer expectations are important drivers of the observed asymmetry in output and employment business cycle variation. ${ }^{3}$

On the other hand, among the studies based on threshold models ${ }^{4}$, Galbraith and Tkacz (2000) use quarterly data for the G7 countries and report empirical evidence of an asymmetric impact on the conditional expectations of output growth rates for US and Canada. They conclude that nonlinear Smooth Transition (STR) models with different regimes can be valuable to model this relationship and can help understand the impact of a regime shift on the relationship between output changes and the spread. ${ }^{5}$ Similarly, Venetis et al. (2003) employ a STR model and find evidence of a strong threshold effect: the relationship between the spread and economic growth rates is stronger if past spread values do not exceed a given positive value. Finally, based on a rational expectation model, Estrella (2005) proves both theoretically and empirically that the relationship between changes in real output and the term spread depends on the coefficients of the monetary reaction function. In particular, the more adverse the policy maker to deviations from target inflation, the weaker the predictive power of the spread on future output changes. In other words, this relationship is not linear as it depends, at least partially, on the monetary regime in use.

As for the predictive power of the spread over future recessions, Estrella and Mishkin (1997) study the issue for France, Germany, Italy, UK and US and find different evidence depending on the country considered: stronger predictive power in US and Germany, weaker in UK and Italy. Dueker (1997) concludes that the spread not only can provide useful information about the likelihood of future US recessions, but it also outperforms other variables, although it can predict neither the precise onset nor the duration of the recessions. Similarly, Bernard and Gerlach (1998)

\footnotetext{
${ }^{3}$ The same Markov-Switching framework is used in many other papers but with different aims: e.g. Vazquez (2004) to investigate the relationship between the term spread and the short rate changes, Kim and Nelson (1999) to predict business cycle turning points of US business cycle.

${ }^{4}$ The smooth transition models were first used by Terasvirta in seminal works, basically aimed to find the best specification for nonlinear time-series. As an example, in Terasvirta and Anderson (1992) smooth transition autoregressive (STAR) models are used to describe various time-series representing business cycles, such as production and unemployment. Similarly, Terasvirta (1995) compares the fit of the annual per capita GNP to the logistic and the exponential smooth transition autoregressive model.

5 Bec et al. (2002) find that the empirical description of monetary policy by linear Taylor rules sensibly improves using a STR form.
} 
find evidence of the spread predictive power on future recession probabilities up to two years ahead in eight countries (Belgium, Canada, France, Germany, Japan, the Netherlands, UK and US over the period 1972-1993). They also test its robustness to the inclusion of countries' leading indicators and report a "cross-country" effect: German and US spreads are particularly significant also in Japan and UK regressions respectively. Sédillot (2001) compares what he defines the "quantitative approach" that uses the spread to forecast economic growth rates with the "qualitative" one, in which the spread is instead used to forecast recession probabilities, and concludes that for all countries considered (France, Germany and US) the htter provides an interesting alternative to the previous one. Moneta (2003) finds evidence in favour of the spread predictive power on future recession probabilities in the whole Euro area. Finally, in Marotta et al. (2006) recession probabilities for the case of Italy are estimated employing a probit model with both domestic and international financial variables. They find that forecasts based on the ISAE (Istituto di Studi e Analisi Economica) chronology are improved if, instead, the ECRI (Economic Cycle Research Institute) chronology is adopted and underline the importance of a further analysis of the chronology selection issue.

\section{The methodology}

\subsection{The spread as predictor of economic growth rates}

Provided that Expectation Hypothesis holds ${ }^{6}$, the predictive power of the term spread on future economic activity can be tested by means of different models. In particular, the linear model could be used, in which lagged values of the spread are used to forecast the change in real economic activity $k$ periods ahead, i.e.:

$$
\Delta y_{t}^{k}=\alpha_{0}+\sum_{i} \beta_{i} s_{t-i}+u_{t}
$$

\footnotetext{
${ }^{6} \mathrm{EH}$ can be tested in different ways ranging from simple regressions to cointegration tests (e.g. see Campbell and Shiller (1991), Boero and Torricelli (2002), Sarno et al. (2005), Kalev and Inder, 2006). Here, a Johansen's procedure has been implemented on interest rates prior to all other analyses. Evidence of cointegration and thus of the EH validity in Italy was found. Detailed results for this analysis are available upon request.
} 
where $u_{t}$ is the disturbance term, $s_{t-i}$ is the $i$-th lag of the term spread, i.e. the difference between long- and short-term interest rates, and $y_{t}$ is the $\log$ of an indicator of real economic activity at time $t$ so that $\Delta y_{t}^{k}$ is the annualized growth of the economic activity over the next $k$ periods. This model, typically used in the early literature, might be in principle too simple to fully capture the nature of relationship between the spread and economic growth rates ${ }^{7}$, which is in fact characterized by nonlinearities either in form of asymmetries (i.e. the relationship differs depending on past values of the spread being positive or negative) and/or of regime switching behaviour (i.e. the informational content of the spread changes with the regime in operation). Hence, in order to test for the potential presence of non-linearity, we run a specific test originally proposed by Luukkonen, Saikkonen and Teräsvirta (1988), hereafter LST test. According to this test, the null of linearity against nonlinearity of model (1) can be tested by first running the following "auxiliary regression":

$$
\Delta y_{t}^{k}=\beta_{00}+\sum_{i}\left(\beta_{0 i} s_{t-d}+\beta_{1 i} s_{t-i} s_{t-d}+\beta_{2 i} s_{t-i} s_{t-d}^{2}+\beta_{3 i} s_{t-i} s_{t-d}^{3}\right)+\varepsilon_{t}
$$

where $\varepsilon_{t}$ is the auxiliary-regression error term, and then testing the following joint-significance hypothesis:

$$
H_{0}: \beta_{1 i}=\beta_{2 i}=\beta_{3 i}=0
$$

Note that the delay parameter $d$ is chosen for each horizon $k$ as the one that minimizes the p-value of the null being tested, i.e. (3). Then, if (3) is rejected, non-linearity of model (1) is substantiated. In fact, the nonlinearities described above can in principle be modelled by means of either MarkovSwitching or Threshold models, whereby the former represent a more general framework in which the latter can be represented as particular cases. However, Priestley (1988) stresses the need to reach a balance between generality and tractability and Tsay (2001) writes: "éstimation of the Markov switching models can be difficult. My own experience shows that in most applications a three-state switching model is needed. The probability transition matrix then involves many parameters, making the model even harder to estimated". In this paper we thus favour tractability

\footnotetext{
${ }^{7}$ See among others Galbraith and Tkacz (2000) and Venetis et al. (2003).
} 
and we model the nonlinearities in the relationship between the term spread and output growth by means of a Threshold model.

Hence, once the LST test proves the presence of nonlinearity, the following STR model can be suitably employed to model the relationship between the term spread and the economic growth rates:

$$
\Delta y_{t}^{k}=\alpha+\sum_{i} \beta_{i} s_{t-i}+\left(\delta+\sum_{i} \phi_{i} s_{t-i}\right) G\left(\gamma, s_{t-d}, c\right)+u_{t}
$$

where the nonlinearity of the model is incorporated in the transition function $G\left(\gamma, s_{t-d}, c\right)$ whose value, bounded between 0 and 1, depends on three different factors: (i) the slope or smoothness parameter $\gamma>0$, that measures the speed of transition from one regime to another; (ii) the transition variable $s_{t-d}$, represented here by the $\operatorname{spread}^{8}$, whose value $d$ periods back determines the current operating regime, and (iii) the threshold $c$, which in a two-regime STR model is a value such that if $s_{t-d}$ lies below $c$ the first regime operates, otherwise the second or alternative regime is activated. $\mathrm{G}$ can be either a logistic function:

$$
G\left(\gamma, s_{t-d}, c\right)=\left(\frac{1}{1+\exp \left\{-\gamma\left(s_{t-d}-c\right) / \sigma_{s_{t-d}}\right\}}\right)
$$

or an exponential function:

$$
G\left(\gamma, s_{t-d}, c\right)=\left(1-\exp \left\{-\gamma\left(s_{t-d}-c\right)^{2} / \sigma_{s_{t-d}}^{2}\right\}\right)
$$

where in both cases $\sigma_{s_{t-d}}$ represents the standard error of the transition variable. Thus, depending on the specification of G, model (4) can either be a Logistic Smooth Transition (LSTR) or an Exponential Smooth Transition (ESTR) model. The LSTR asymmetry depends on the threshold $c$, which can be 0 or any other positive or negative value. Similarly, ESTR is symmetric w.r.t $c$

\footnotetext{
${ }^{8}$ Along with the spread, Venetis et al. (2003) consider several other variables as potential transition variables, such as past growth rates in aggregate economic activity, quarterly output-gap and time. However, as the null of linearity is rejected using all the variables and 'the strongest rejections correspond to the spread [...]', they 'finally retain the lagged spread as the transition variable".
} 
because it displays the same dynamics for values of $s_{t-d}$ far higher and lower than $c$ and a different one for values of $s_{t-d}$ nearby $c$. The choice between LSTR and ESTR can be theoretically and/or empirically grounded. Theoretically, the former seems more suitable for modelling the relationship under analysis because high preads typically suggest increasing economic growth while low spreads usually point at a growth slowdown. Nevertheless, as in Venetis et al. (2003), the choice can be made empirically by testing the following sequence of null hypotheses:

$$
\begin{aligned}
& H_{0}^{1}: \beta_{3 i}=0 \\
& H_{0}^{2}: \beta_{2 i}=0 \mid \beta_{3 i}=0 \\
& H_{0}^{3}: \beta_{1 i}=0 \mid \beta_{2 i}=\beta_{3 i}=0
\end{aligned}
$$

on the auxiliary regression (2). If the p-value for the F-Statistics of $H_{0}^{2}$ is lower than that for $H_{0}^{1}$ and $H_{0}^{3}$, then the exponential function is chosen, otherwise the logistic specification of $\mathrm{G}$ is preferred.

\subsection{The spread as predictor of recession probabilities}

A second approach to test the information content of the TSIR is based on the predictability view of the business cycle and uses the term spread to predict economic recession $k$ periods ahead. The dependent variable used in this case, named recession, is an indicator variable assuming value 1 if the economy is in a recession and 0 otherwise. Following Estrella and Hardouvelis (1991) and Estrella and Mishkin (1997), a probit model can be used ${ }^{9}$ :

$$
P\left(\text { recession }_{t}\right)=F\left(\alpha_{0}+\alpha_{1} s_{t-k}\right)
$$

where $F$ indicates the normal cumulative distribution function. If $\alpha_{1}$ is statistically significant, then the spread contributes to predict future recession probabilities and fitted values are the estimated probabilities of the economy being in a recession $k$ periods ahead conditional on the information in

\footnotetext{
${ }^{9}$ A logit model could alternatively be used (as in Sensier et al., 2004). In this paper a logit model was estimated on the same dataset with similar results and hence it is not presented.
} 
the current term spread. In order to test the robustness of the predictive power of the spread, the role of additional variables can be tested by means of the following regression:

$$
P\left(\text { recession }_{t}\right)=F\left(\alpha_{0}+\alpha_{1} s_{t-k}+\alpha_{2} X_{t-k}\right)
$$

where $X_{t-k}$ is a vector of additional explanatory variable(s). If $\alpha_{1}$ is significant in (10) but not in (11), then the predictive power of the spread is not robust to the inclusion of other informative variables. Finally, the contribution of the spread in predicting future recession probabilities is evaluated on the basis of in- and out-of-sample forecasts. To this end, forecast performances of model (10) can be compared with those of a benchmark model including the OECD composite Leading Indicator (LI) only, i.e.:

$$
P\left(\text { recession }_{t}\right)=F\left(\alpha_{0}+\alpha_{2} L I_{t-k}\right)
$$

The in-sample forecasts of models (10) and (12) are compared on the basis of the number of Hits (i.e. the model predicts recession when there is indeed recession) and of False Alarms (i.e. the model predicts recession when it does not occur). The out-of-sample forecast performances of the two models are compared by means of three measures: the Quadratic Probability Score (QPS), the Log Probability Score (LPS) and the Kuipers Score (KS). QPS is a loss function bounded between 0 and 2 defined as:

$$
Q P S=\frac{2}{T} \sum_{t=1}^{T}\left(\tilde{p}_{t}-\text { recession }_{t}\right)^{2}
$$

where $\tilde{p}_{t}$ are the fitted recession probabilities. LPS is a non-negative function, which penalizes large mistakes more than QPS and is computed as follows:

$$
\text { LPS }=-\frac{1}{T} \sum_{t=1}^{T}\left[\left(\text { recession }_{t}\right) * \ln \left(\tilde{p}_{t}\right)+\left(1-\text { recession }_{t}\right) * \ln \left(1-\tilde{p}_{t}\right)\right]
$$

Finally, KS by construction penalizes "one-prediction" models, i.e. those forecasting always recession or expansion, as it is defined as the difference between the percentage of Hits $(\mathrm{H})$ and the percentage of False Alarms (F), respectively computed as: 


$$
H=\frac{\sum_{t=1}^{T}\left(\text { recession }_{t}\right) * I\left(\tilde{p}_{t} \geq \bar{p}\right)}{\sum_{t=1}^{T}\left(\text { recession }_{t}\right)} \quad \text { and } \quad F=\frac{\sum_{t=1}^{T}\left(1-\text { recession }_{t}\right) * I\left(\tilde{p}_{t} \geq \bar{p}\right)}{\sum_{t=1}^{T}\left(1-\text { recession }_{t}\right)}
$$

where $\bar{p}$ is a threshold value (bigger than the sample proportion) such that for $\tilde{p} \geq \bar{p}$ the model predicts recession.

Since several studies in the existing literature highlight the sensitivity of the results to the business cycle chronology adopted, we also examine the forecast performances of the term spread under two different chronologies, namely the ECRI and the ISAE chronologies. The two alternatives are chosen based on the following observations: the former is among the most widespread in the literature and the latter is specific to the Italian case.

\section{Dataset and Empirical Results}

The dataset ${ }^{10}$ spans over the period December 1983 - July 2005 and includes monthly observations for four variables in Italy: the spread, the OECD Composite Leading Indicator, a proxy for the economic activity and a dummy variable for the recession. A few observations are here in order. First, different measures of the term spread have been proposed in literature (e.g. see Harvey (1989) and Dueker, 1997). This paper sticks to the most widespread one: the spread between 10year and 3-month rates, whereby the former is represented by the 10-year Italian Government Bond Yield and the latter by the 3-month Eurorate. Second, as a proxy for real activity the seasonally adjusted Index of Industrial Production has been preferred to the GDP since data for the latter are available only on a quarterly basis. Finally, the selection of a particular business cycle chronology is a relevant issue. ${ }^{11}$ In fact, since a precise dating of recessions is quite difficult, different sources usually provide different chronologies: this emerges quite clearly by comparing the Italian business cycle chronologies proposed by the Economic Cycle Research Institute (ECRI), the Istituto di Studi

\footnotetext{
${ }^{10}$ Data source: Datastream.

11 Business cycle dating is not the aim of this paper, but it is a very important issue which has fostered a specific literature also for the case of Italy: see Otranto (2005) and Bruno and Otranto (2004).
} 
e Analisi Economica (ISAE) and the OECD. As far as we know, the only previous work focused on Italy, Marotta et al. (2006), adopts the ISAE and ECRI chronologies. Thus, in order to evaluate the sensitivity of the results to the chronology considered, in the present paper the dummy variable for recession has been created according to the OECD chronology (see Table 1), which differs from the ISAE and ECRI ones for capturing minor cycles too. ${ }^{12}$ More precisely, we assign to each month in the sample value 1 if falling within a recession, i.e. between a peak and a trough, and 0 otherwise.

\section{[Table 1]}

\subsection{The spread as predictor of economic growth rates}

As a first step, the linear model (1) is estimated for the forecast horizons $k=3,6,12,24$ and including all lagged term spread ( $i=1,3,6,12,18,24$ months). Nevertheless, the obtained results are quite poor $^{13}$ : in most predictive horizons examined the last-two-year spread only turns out to be significant, the estimated coefficients display signs opposite to the expectations, i.e. minus, and the overall $\mathrm{R}^{2}$ is quite low, ranging between $3 \%$ and $13 \%$. Models such as (1) in fact do not take into account the different effects that the spread could in principle have on the growth rates depending on its value being high or low. We thus test for nonlinearity in (1) by means of the specific LST test, which also allows the determination of the delay parameter $d$ for each forecast horizons (Table 2).

\section{[Table 2]}

As reported in Table 3, the null of linearity (i.e. equation (3)) is strongly rejected for all forecast horizon $k$, proving that a linear model may not fully capture the nonlinearities associated with the relation holding between interest rates spread and economic growth rates.

[Table 3]

\footnotetext{
${ }^{12}$ Different chronologies may be associated to different business cycle dynamics in terms of possible asymmetries. An investigation of the symmetric vs. asymmetric nature of the business cycle goes beyond the scope of this paper, but a renewed interest in the issue is present in the literature (e.g. Stanca (1999), Andreano and Savio (2002), Peirò, 2004).

${ }^{13}$ Detailed results are available upon request.
} 
Hence, in line with the most recent literature, we implement the STR model (4), which could either be a LSTR or an ESTR depending on the transition function G being respectively logistic or exponential. Even if the former seems theoretically more appropriate, in the present paper the final choice is carried out following Venetis et al. (2003) on an empirical basis, by testing the sequence of null hypotheses (7)-(9) on the auxiliary regression (2). Consistently with what suggested by theory, the logistic specification for $\mathrm{G}$ is chosen as the p-values for $H_{0}^{2}$ F-test are systematically bigger than those for the other two hypotheses (see Table 4).

\section{[Table 4]}

Thus, the nonlinear model estimated with Nonlinear Least Squares (NLS) is specified as

$$
\Delta y_{t}^{k}=\alpha+\sum_{j=1}^{12} \rho_{j} \Delta y_{t-j}^{k}+\sum_{i} \beta_{i} s_{t-i}+\left(\delta+\sum_{j=1}^{12} \omega_{j} \Delta y_{t-j}^{k}+\sum_{i} \phi_{i} s_{t-i}\left(\frac{1}{1+\exp \left\{-\gamma\left(s_{t-d}-c\right) / \sigma_{s_{t-d}}\right.}\right\}\right)+u_{t}
$$

where the model specification includes also $j$ autoregressive components in response to the autocorrelation observed in the residuals. In particular, given the monthly frequency of the data, we set $j=12$. Estimates are expected to be positive for $\beta_{i}$ and negative for $\phi_{i}$. In other words, if the lagged value of the spread is lower than $c$, i.e. the first regime is activated, an increase in the spread points to an increase in the economic activity, while if the second regime is active (i.e. if the spread is already exceptionally high and above the positive threshold $c$ ) an additional increase in the spread leads to a reduction in economic growth.

A general-to-specific approach is adopted to select the significant spreads: all lagged spreads $(i=1,3,6,12,18,24$ months) are initially included, then the non-significant ones are sequentially eliminated and the nonlinear models re-estimated till the appropriate final specifications are found. As the initial NLS estimates for $\gamma$ (see Table 5) are always very high, indicating that only a few 
observations are actually near the threshold $c$, they are replaced with a ceiling value of 100 and the models are re-estimated. ${ }^{14}$

\section{[Table 5]}

The results obtained by estimating model (4') over the whole sample period confirm the need for a nonlinear (threshold) specification as the $\sigma_{N L} / \sigma_{L}$ ratio is always ess than one and the $\mathrm{R}^{2}$ are satisfactory, ranging between $48 \% \quad k=3)$ to $83 \% \quad k=24) .{ }^{15}$ Nevertheless, the evidence found is generally neither consistent with expectations nor across the forecast horizons. This might in principle stem from either an inappropriate model specification (i.e. despite the presence of nonlinearity is validated, the LSTR model might not be the one that best captures the relation under analysis) or the period considered, which in fact includes for the Italian case major macroeconomic events. Specifically, after a turbulent period at the end of 1992 the Italian Lira was devaluated and the Italian currency abandoned the SME. Based on the latter observation, model (4') is re-estimated over a subsequent period, namely Jan 1993 - Jul 2005.

\section{[Table 6]}

Results of the NLS estimation for each forecast horizon $(k=3,6,12,24$ months $)$ are reported in Table 6 and are quite good. First, the need for a nonlinear specification is again confirmed by the $\sigma_{N L} / \sigma_{L}$ ratio always less than one. Second, the fit of the model seems much better when the subsample is considered: the $\mathrm{R}^{2}$ ranges between $\left.82 \% \quad k=3\right)$ to $95 \% \quad(k=24)$. In addition, across all forecast horizons $k$, the most significant coefficients are associated with the last-year and last-twoyear spreads, thereby showing that the term spread has a significant role as an explanatory variable of economic growth rates, even if with some delay. Furthermore, the estimated coefficients display the expected signs: $\beta_{i}$ coefficients have positive signs (i.e. when the first regime is activated a positively sloped term structure suggests an increase in the output growth rates) while $\phi_{i}$ have

\footnotetext{
14 This procedure is in line with Venetis et al. (2003) and could in principle lead to inconsistent estimates; however, provided that $\gamma$ is sufficiently large, the bias is practically negligible.

${ }^{15}$ Detailed results are available upon request.
} 
negative signs (i.e. when the alternative regime is activated, a further increase in the term spread generally leads to lower expected output growth rates).

\subsection{The spread as predictor of recession probabilities}

Table 7 reports the estimation output over forecast horizons of 3, 6, 12 and 24 months of the probit model (10). The coefficients associated with the spread all have the correct theoretical sign (i.e. negative) and, except for $\mathrm{k}=12$, they are all strongly significant, with estimated values varying between -0.21 and -0.42 . Italian data thus corroborate the existence of a significant link between the spread and recession probabilities.

\section{[Table 7]}

In order to test the robustness of this result, the model is re-estimated including an additional explanatory variable. While some authors (e.g Estrella and Mishkin, 1997) include into the model more than one variable, in this paper only the OECD LI is considered as it already encloses several economic indicators. ${ }^{16}$ Table 8 thus reports the estimation output of the probit model (11). The coefficients associated with LI are never statistically different from zero while, consistently with the results for model (10), the spread coefficients remain strongly significant and negatively signed in all cases but $\mathrm{k}=12$. Furthermore, the inclusion of LI into the model produces only minor changes in both fit measures McFadden $\mathrm{R}^{2}$ and $\phi$, suggesting that no relevant improvement of the model is produced when LI is included. Therefore Italian data not only confirm the link existing between the term spread and future recession probabilities, but also prove its robustness to the inclusion of an additional informative variable such as LI.

[Table 8]

\footnotetext{
16 See www.oecd.org for additional information.
} 


\section{Forecast analysis}

The predictive power of the spread can be evaluated also by means of its forecast ability. Since forecasts with nonlinear LSTR model are quite demanding ${ }^{17}$, in this paper the forecast analysis is conducted by means of the probit model which allows for simpler but still effective forecasts. More precisely, in- and out-of-sample forecasts of the model (10), including the term spread, are compared with those of the benchmark model (12), including the OECD composite Leading Indicator (LI). In order to compute the number of Hits and False Alarms, we assume that the model predicts a recession when $\tilde{p}_{t} \geq 0.55$. For the model to predict a recession the fitted probability must increase above the sample proportion, in this case $0.5231 .{ }^{18}$ It follows that the rule adopted in other papers, i.e. $\tilde{p}_{t} \geq 0.5$, cannot be implemented here since the model would always predict recessions. Hence, in order to compensate for the prudential chronology which is peculiar to OECD, a slightly higher but still reasonable threshold is chosen.

The number and proportion of Hits and False Alarms of the in-sample forecasts for both models are reported in Table 9. Overall, the model including the spread displays a higher number of Hits and a smaller (or in one case equal) number of False Alarms. Thus, in-sample forecasts confirm that the spread actually adds useful information to predict future recessions and hence substantiate its predictive power.

\section{[Table 9]}

Out-of-sample forecasts are computed over the period January 1995 - July 2005 and are evaluated on the basis of three measures: the Quadratic Probability Score (QPS), the Log Probability Score (LPS) and the Kuipers Score (KS). Table 10 reports a comparison between the two models. Lossfunctions QPS and LPS always display lower values and KS always higher values in the model including the spread, hence further supporting its additional predictive power.

\footnotetext{
${ }^{17}$ See for instance Granger and Teräsvirta (1993) and Clements et al. (2004).

${ }^{18}$ Recall that the OECD chronology reports also minor cycles and thus in our sample it turns out that 136 periods (out of 260) are classified as recessions.
} 
[Table 10]

In sum both in- and out-of-sample forecasts prove that the term spread can provide useful information to forecast future recessions in Italy. Based on this evidence, the spread is employed to predict future recessions and the fitted recession probabilities of model (10) are compared with actual recessions as from the OECD chronology (see Figure 1).

[Figure 1]

By a visual inspection of the graph, two main observations are apparent. First, there is quite a marked difference in the predictive power of the spread between the period 1984-1991 and the period 1992-2005, whereby in the latter forecasts appear to be more accurate than in the former. The spread alone actually predicts all major recessions (Oct.91-Dec.93, Jan.96-May.99, Jan.01Nov.01), it gives just one False Alarm in July 1995 and captures the shorter recessions occurring during the last five years and reported by OECD chronology. As for the period 1984-1991, the somewhat unsatisfactory forecasts are not totally surprising if we recall that this period, by contrast to the following one, contains the only cycles, which are registered by the OECD although marked as minor ones (see Table 1).

Second, and in relation with the latter observation, most false predictions can be reinterpreted in connection with alternative business cycle chronologies. For example, the 1986 and 1990 predictions of an expansion, which are wrong according to the OECD chronology, are consistent with the both the ISAE and ECRI chronology (see Table 11). As for the 1995 false alarm, it should be stressed that the dating of the turning point in those years was particularly difficult (see Altissimo et al., 2000).

\section{[Table 11]}

In the light of the latter observations and of the sensibility of the results to the business cycle chronology adopted, the forecast performances of the term spread under the OECD chronology (both in- and out-of-sample) are compared to those obtained by adopting different chronologies, 
namely the ISAE and ECRI ones. As far as the in-sample forecast performances are concerned the percentages of Hits and False Alarm sensibly differ across the various chronologies (see Table 12).

[Table 12]

Regardless of the model in fact the OECD chronology leads to sensibly higher percentages of Hits compared to both the other chronologies considered. On the other hand, it also displays the higher number of False Alarms, probably as a consequence of the particular prudence peculiar of this chronology stemming from the inclusion of minor cycles too. Nevertheless, the predictive power of the term spread is confirmed since also for ECRI and ISAE chronologies the model including the spread leads to generally higher percentages of Hits and lower percentages of False Alarms compared to the model including the LI.

The out-of-sample forecast performances also substantially vary across the different chronologies (see Table 13). However, the results obtained overall substantiate the predictive power of the term spread compared to the LI, as with the only exception of the ECRI chronology, the model including the spread generally leads to lower QPS and LPS and higher KS. Furthermore, by comparing the forecast performances of model (10) across all the chronologies, it emerges that OECD chronology overall leads to better performances, especially over longer forecast horizons.

[Table 13]

In sum, results indicate that, given difficulties in business cycle dating (e.g. Bruno and Otranto, 2004), the selection of an appropriate business cycle chronology has to be done with special attention not only to the specific country, but also to the time period under consideration.

\section{A comparison with the literature}

A few recent papers have tested the informative content of Italian term spread w.r.t. recession probabilities: Estrella and Mishkin (1997), Moneta (2003), Sensier et al. (2004), and Marotta et al. (2006). Dataset frequency, model estimated and chronology used in each of these studies are 
reported in Table 14 from which it is apparent that the present paper differs from previous works both for methodology and dataset.

\section{[Table 14]}

Estrella and Mishkin (1997) analyse the informative content of term spread on real activity in Italy at a comparative level with France, Germany, UK and US. As for Italian case they report that the term spread has a predictive power on recession probabilities up to one and two years ahead and the result is robust to the inclusion of other monetary indicators. Moneta (2003) tests the predictive power of the spread in Italy, France and Germany to check whether evidence for the whole Euro area, which is basically the focus of the paper, and for single countries are consistent. Even if less strong than in Germany, the author finds a significant predictive power of the term spread also in Italy and shows that the spread is more powerful than the OECD Composite Leading Indicator in forecasting recessions. Sensier et al. (2004) test the predictive power of the term spread on recession probabilities three-months ahead in Italy together with Germany, France, and UK. Even if here a logistic rather than a probit model is used, a significant informative content of the term spread is reported. Marotta et al. (2006) estimate recession probabilities for an application to the Basel II capital requirement formula, performing the forecast within a probit model and comparing two different chronologies, namely ISAE and ECRI ones. In both cases evidence in favour of the term spread predictive power is found, even if forecast performance sensibly improves when ECRI chronology is adopted.

By a comparative inspection between the results in this paper and previous ones, two main remarks are in order. First, in line with the literature the predictive power of the spread is here validated, despite different approaches, dataset and chronologies are adopted. Thus, the overall informative content of the term spread turns out to be robust to the methodology used for the empirical analysis. On the other hand, some results appear to be sensitive to the setup taken in the empirical investigation (recalled in Table 10). Sensier et al. (2004) observe that the predictive power of the spread is not maintained when other informative variables are considered. In contrast, the 
robustness of the informative content of the term spread to the inclusion of additional variables is here validated, in line with Estrella and Mishkin (1997), Moneta (2003) and Marotta et al. (2006). Furthermore, our results indicate that the term spread predictive power is stronger for long forecast horizons, i.e. up to two years ahead as in Estrella and Mishkin (1997), in contrast to Moneta (2003) that reports the informative content decreasing with the forecast horizons. Finally, in line with the only paper focused on the regime prediction specifically for the Italian case, i.e. Marotta et al. (2006), the results reported in this study prove the importance of adopting the right chronology for the business cycle forecast.

\section{Conclusions}

Despite a rich empirical literature on the information and predictive content of the term spread on real economic activity, only a few works have analysed this issue for the Italian case. This study differs from the previous ones on the Italian case for the dataset, the business cycle chronology and the methodology used. First, a more recent (December 1983 - July 2005) and higher frequency (monthly rather than quarterly observations) dataset is used, whereby the latter feature allows a better match between the business cycle chronology and the classification of recession/expansion periods in the sample under analysis. Second, as previous works stress the sensitivity of the results to the chronology used (see Moneta (2003) and Marotta et al., 2006), the OECD chronology, never used in previous works related to Italian case, is here adopted. Finally, two approaches are implemented to assess the informative content of the term spread on real activity: in the first the spread is used to forecast economic growth rates while in the second it is used as predictor of future recession probabilities. As for the former the nonlinear Logistic Smooth Transition (LSTR) model is estimated implementing a general-to-specific procedure to find the best specification for each forecast horizon under analysis. As for the second approach, a binary probit model is employed, using as explanatory variables either the spread alone or the spread along with the OECD Composite Leading Indicator (LI). Both implementations offer results which support the 
informative and predictive content of the term spread in Italy, although the evidence is more satisfactory as from 1993, i.e. after the turbulent period that characterized Italian money markets in 1992. Specifically, estimated coefficients are overall significant, in particular those associated with last 1- and 2-year lag spreads, consistently with economic theory and empirical evidence generally reported in previous studies. Moreover, in- and out-of-sample probit forecast performances are evaluated, proving that the term spread can actually provide valuable information to forecast Italian business cycle and that the forecasts based on the term spread overall perform better than those based on the OECD LI. Finally, a comparative analysis of the forecast performances of the term spread across different business cycle chronologies highlights that the OECD one adopted here overall provides better out-of-sample forecasts, especially over longer forecast horizons.

These results are of interest in various applications and specifically in finance. In this respect, it has to be stressed that when regime forecasts are used in real applications, the selection of the business cycle chronology is possibly the most important issue because results appear to be sensitive to it. In particular, the results reached in this paper show that the choice has to be done with special attention to the specific feature of the country and the specific time period under consideration. A joint investigation of the business cycle dating issue and the business cycle prediction certainly deserves a separate study.

\section{ACKNOWLEDGMENTS}

The authors gratefully acknowledge support from MIUR (Prin 2005139555_001) and wish to thank Gianna Boero and Michael P. Clements for helpful suggestions on a previous version of the present work. Usual caveats apply. 


\section{References}

Altissimo, F., Marchetti, D. J. and Oneto, G. P. (2000) The Italian business cycle: coincident and leading indicators and some stylized facts, Temi di Discussione Banca d'Italia, 377.

Andreano, M.S. and Savio, G. (2002) Further evidence on business cycle asymmetries in G7 countries, Applied Economics, 34, 895-904.

Ang, A., Piazzesi, M. and Wei, M. (2006) What does the yield curve tell us about GDP growth?, Journal of Econometrics, 131, 359-403.

Artis, M., Krolzig, H. M. and Toro, J. (2004) The European business cycle, Oxford Economic Papers, 56, 1-44.

Bec, F., Ben Salem, M. and Collard, F. (2002) Asymmetries in monetary policy reaction function: evidence fr the U.S., French and German Central Banks, Studies in Nonlinear Dynamics and Econometrics, 6, 40-62.

Bernard, H. and Gerlach, S. (1998) Does the term structure predict recessions? The international evidence, International Journal of Finance and Economics, 3, 195-215.

Boero, G. and Torricelli, C. (2002) The information in the term structure of German interest rates, European Journal of Finance, 8, 21-45.

Bruno, G. and Otranto, E. (2004) Dating the Italian Business Cycle: a comparison of procedures, Working Paper ISAE, N. 41.

Campbell, J.Y. and Shiller, R.J. (1991) Yield spreads and interest rate movements: A bird's eye view, Review of Economic Studies, 58, 495-514.

Clements, M.P., Franses, P. H. and Swanson, N. R. (2004) Forecasting economic and financial time-series with non-linear models, International Journal of Forecasting, 20, 169-183.

Duarte, A., Venetis, J. and Paya I. (2005) Predicting real growth and the probability of recession in the Euro area using the yield spread, International Journal of Forecasting, 21, 262-277.

Dueker, J. (1997) Strengthening the case for the yield curve as predictor of U.S. recessions, Federal Reserve Bank St. Louis Review, 79, 41-51. 
Estrella, A. (2005) Why does the yield curve predict output and inflation?, The Economic Journal, 115, $722-744$.

Estrella, A. and Hardouvelis, G. (1991) The term structure as a predictor of real economic activity, Journal of Finance, 46, 555-576.

Estrella, A. and Mishkin, F.S. (1997) The predictive power of the term structure of interest rates in Europe and the United States: implications for the European Central Bank, European Economic Review, 41, 1375-1401.

Estrella, A. and Mishkin, F.S. (1998) Predicting U.S. recessions: financial variables as leading indicators, Review of Economics and Statistics, 1, 45-61.

Galbraith, J.W and Tkacz, G. (2000) Testing for asymmetry in the link between the yield spread and output in the G-7 countries, Journal of International Money and Finance, 19, 657-672.

Granger, C.W.J. and Teräsvirta, T. (1993) Modelling Nonlinear Dynamic Relationships, Oxford University Press.

Harvey, C.R. (1988) The real term structure and consumption growth, Journal of Financial Economics, 22, 305-334.

Harvey, C.R. (1989) Forecasts of economic growth from the bond and stock markets, Financial Analysts Journal, 45, 38-45.

Harvey, C.R. (1993) The term structure forecasts economic growth, Financial Analyst Journal , 49, 6-8.

Kalev, P.S. and Inder, B.A. (2006) The information of the term structure of interest rates, Applied Economics, 38, 33-45.

Kim, C. and Nelson, C. R. (1999) Has the U.S. Economy Become More Stable? A Bayesian Approach Based on a Markov-Switching Model of the Business Cycle, Review of Economics and Statistics, 81, 608-16. 
Korenok, O., Mizrach, B. and Radchenko, S. (2004), The Microeconomics of Macroeconomic Asymmetries: Sectoral Driving Forces and Firm Level Characteristics, Rutgers University Economics Department Working Paper N 5, 1-20.

Luukkonen, R., Saikkonen, P. and Teräsvirta, T. (1988) Testing linearity against Smooth Transition Autoregressive Models, Biometrika, 75, 491-499.

Marotta, G., Pederzoli, C. and Torricelli, C. (2006) Forward-looking estimation of default probabilities with Italian data, Euro-Mediterrenean Economics and Finance Review, 1, 6-15.

Moneta, F. (2003) Does the yield spread predict recessions in the Euro area?, European Central Bank Working Paper Series, Working Paper Nº 294.

Otranto, E. (2005) Extracting a common cycle from series of different frequency: an application to the Italian economy, Journal of Business Cycle Measurement and Analysis, 2, 407-29

Pederzoli, C. and Torricelli, C. (2005) Capital requirements and Business Cycle regimes: forwardlooking modelling of default probabilities, Journal of Banking and Finance, 29, 3121-3140.

Peirò, A. (2004) Are business cycles asymmetric? Some European evidence, Applied Economics, 36, 335-342.

Plosser, C.I. and Rouwenhorst, G.K. (1994) International term structures and real economic growth, Journal of Monetary Economics, 33, 133-155.

Sarno, L., Thornton, D. L. and Valente G. (2005) The empirical failure of the Expectations Hypothesis of the term structure of bond yields, Journal of Financial and Quantitative Analysis, forthcoming.

Sédillot, F. (2001) La pente des taux contient-elle de l'information sur l'activité économique future?, Economie et Prévision, 147, 141-57.

Sensier, M., Artis, M., Osborn, D. and Birchenhall, C. (2004) Domestic and international influences on business cycle regimes in Europe, International Journal of Forecasting, 20, 343-357. 
Stanca, L. (1999) Asymmetries and nonlinearities in Italian macroeconomic fluctuations, Applied Economics, 31, 483-491.

Stock, J. H. and Watson, M. H. (2003) Forecasting output and inflation: the role of asset prices, Journal of Economic Literature, 41, 788-829.

Terasvirta, T. (1995) Modelling Nonlinearity in U.S. Gross National Product 1889-1987, Empirical Economics, 20, 577-97.

Terasvirta, T. and Anderson, H. M. (1992) Characterizing Nonlinearities in Business Cycles Using Smooth Transition Autoregressive Models, Journal of Applied Econometrics, 7,S119-S136.

Tsay, R.S. (2001) Nonlinear Time Series Models: Testing and Applications, in A Course in Time Series Analysis, Peña D., Tiao G.C., Tsay, R.S. (Eds.), John Wiley and Sons.

Vázquez J. (2004) Switching Regimes in the Term Structure of Interest Rates during U.S. PostWar: A Case for the Lucas Proof Equilibrium?, Studies in Nonlinear Dynamics \& Econometrics, 8, 1122-1122.

Venetis, I.A., Paya, I. and Peel, D.A. (2003) Re-examination of the predictability of economic activity using the yield spread: a nonlinear approach, International Review of Economics \& Finance, 12, 187-207. 
Table 1: Turning points of the Italian business cycle

\begin{tabular}{lll}
\hline \multicolumn{1}{c}{ Peak } & \multicolumn{1}{c}{ Trough } & $\begin{array}{c}\text { Duration } \\
\text { (in months) }\end{array}$ \\
\hline-- & May 1983 & -- \\
\hline (August 1984) & (January 1987) & 30 \\
\hline December 1989 & (April 1991) & 16 \\
\hline (September 1991) & December 1993 & 27 \\
\hline December 1995 & May 1999 & 41 \\
\hline December 2000 & November 2001 & 11 \\
\hline July 2002 & May 2003 & 11 \\
\hline January 2004 & \multicolumn{1}{c}{--} & -- \\
\hline \hline
\end{tabular}

Source: OECD (see www.oecd.org), minor cycles appear in brackets

Table 2: Grid search for d, by predictive horizon $k$

\begin{tabular}{ccccc:ccccc}
\hline \hline \multirow{2}{*}{$\mathbf{d}$} & \multicolumn{4}{c}{ Probability } & \multicolumn{3}{c}{ Probability } \\
\cline { 2 - 10 } & $K=3$ & $K=6$ & $K=12$ & $K=24$ & & $K=3$ & $K=6$ & $K=12$ & $K=24$ \\
\hline 1 & 0.049 & 0.005 & $\mathbf{0 . 0 0 0}$ & 0.000 & 7 & 0.007 & 0.565 & 0.010 & 0.000 \\
\hline 2 & 0.001 & $\mathbf{0 . 0 0 0}$ & 0.000 & 0.000 & 8 & 0.012 & 0.699 & 0.011 & 0.000 \\
\hline 3 & $\mathbf{0 . 0 0 0}$ & 0.014 & 0.000 & 0.000 & 9 & 0.001 & 0.957 & 0.068 & 0.000 \\
\hline 4 & 0.000 & 0.087 & 0.000 & 0.000 & 10 & 0.004 & 0.563 & 0.081 & 0.000 \\
\hline 5 & 0.218 & 0.152 & 0.000 & 0.000 & 11 & 0.154 & 0.612 & 0.099 & $\mathbf{0 . 0 0 0}$ \\
\hline 6 & 0.021 & 0.237 & 0.007 & 0.000 & 12 & 0.447 & 0.169 & 0.122 & 0.000 \\
\hline \hline
\end{tabular}

Note: bold values are the minima.

Table 3: LST nonlinearity test, by forecast horizon.

\begin{tabular}{ccccc}
\hline K & d & F-statistic & df & Probability \\
\hline \hline 3 & 3 & 4.939046 & $(18,214)$ & 0.0000 \\
6 & 2 & 4.849099 & $(18,214)$ & 0.0000 \\
12 & 1 & 15.42899 & $(18,214)$ & 0.0000 \\
24 & 11 & 8.121377 & $(18,214)$ & 0.0000
\end{tabular}


Table 4: The choice of the transition function specification

\begin{tabular}{cccc|cc|cc}
\hline \hline \multirow{2}{*}{$\mathbf{k}$} & $\mathbf{d}$ & \multicolumn{2}{|c|}{$H_{0}^{1}: \beta_{3 i}=0$} & \multicolumn{2}{|c}{$H_{0}^{2}: \beta_{2 i}=0 \mid \beta_{3 i}=0$} & \multicolumn{2}{|c}{$H_{0}^{3}: \beta_{1 i}=0 \mid \beta_{2 i}=\beta_{3 i}=0$} \\
\cline { 2 - 8 } & & F-stat & p-value & F-stat & p-value & F-stat & p-value \\
\hline \hline 3 & 3 & 3.057 & 0.007 & 1.620 & 0.143 & 1.735 & 0.114 \\
6 & 2 & 5.497 & 0.000 & 5.342 & 0.000 & 6.661 & 0.000 \\
12 & 1 & 10.212 & 0.000 & 2.804 & 0.012 & 10.611 & 0.000 \\
24 & 11 & 9.624 & 0.000 & 2.371 & 0.031 & 3.307 & 0.004 \\
\hline
\end{tabular}

Table 5: Initial estimates for $\gamma$

\begin{tabular}{cc}
\hline $\begin{array}{c}\text { Forecast } \\
\text { horizon }\end{array}$ & Estimates \\
\hline $\mathbf{k}=\mathbf{3}$ & 258.0350 \\
$\mathbf{k}=\mathbf{6}$ & 282.5378 \\
\hline $\mathbf{k}=\mathbf{1 2}$ & 289.2488 \\
$\mathbf{k}=\mathbf{2 4}$ & 270.3917 \\
\hline
\end{tabular}

Table 6: Estimation output of the LSTR model (Jan 1993 - July 2005).

\begin{tabular}{|c|c|c|c|c|c|c|c|c|c|}
\hline Model & $\Delta v^{k}=$ & $-\sum^{12} \wedge$ & & $\Gamma$ & $+(\delta+)^{12} \omega$ & $v^{k}+\Gamma_{\phi}$ & \multicolumn{2}{|r|}{1} & $+u_{t}$ \\
\hline$\overline{\mathbf{k}}$ & \multicolumn{2}{|c|}{3} & & \multicolumn{2}{|r|}{$\overline{c 6}$} & \multicolumn{2}{|r|}{$\overline{112}$} & \multicolumn{2}{|r|}{24} \\
\hline d & \multicolumn{2}{|c|}{3} & & & $P$ & \multicolumn{2}{|r|}{1} & \multicolumn{2}{|r|}{11} \\
\hline Coeff. & \multicolumn{3}{|c|}{ Estimate } & Coeff. & Estimate & Coeff. & Estimate & Coeff. & Estimate \\
\hline$\alpha$ & \multicolumn{2}{|c|}{$0.559 * * *$} & 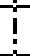 & $\alpha$ & $0.589 * * *$ & $\bar{\alpha}$ & $0.531 * * *$ & $\alpha$ & $0.456 * * *$ \\
\hline$\beta_{12}$ & \multicolumn{2}{|c|}{$2.577 * * *$} & & $\beta_{12}$ & $1.634 * * *$ & $\beta_{12}$ & $0.438^{* *}$ & $\beta_{12}$ & $0.450 * * *$ \\
\hline$\beta_{24}$ & \multicolumn{2}{|c|}{$1.969 * * *$} & j & $\beta_{24}$ & $0.827 *$ & $\beta_{24}$ & $0.263^{*}$ & - & - \\
\hline$\delta$ & \multicolumn{2}{|l|}{0.607} & & $\overline{\bar{\delta}}$ & -0.145 & 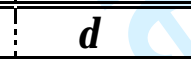 & -0.240 & 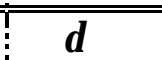 & -0.585 \\
\hline$\phi_{12}$ & \multicolumn{2}{|c|}{$-3.328 * * *$} & 1 & $\phi_{12}$ & $-1.817 * * *$ & $\phi_{12}$ & $-0.498^{*}$ & $\phi_{12}$ & $-0.489 * * *$ \\
\hline$\phi_{24}$ & \multicolumn{3}{|c|}{$-3.221 * * *$} & $\phi_{24}$ & $-1.462 * * *$ & $\phi_{24}$ & $-0.674 * *$ & - & - \\
\hline $\mathrm{c}$ & \multicolumn{2}{|c|}{$0.472 * * *$} & & $\mathrm{c}$ & $0.464 * * *$ & $\mathrm{c}$ & $0.480 * * *$ & c & $0.472 * * *$ \\
\hline$\overline{\mathrm{R}^{2}}$ & \multicolumn{2}{|c|}{0.817} & i & & $\overline{9901}$ & 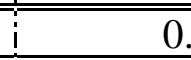 & .945 & 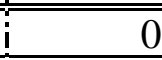 & .951 \\
\hline Adjusted $\mathrm{R}^{2}$ & & 56 & i & & 868 & 0 . & .926 & 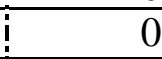 & .934 \\
\hline$\sigma_{N L} / \sigma_{L}$ & & 98 & ! & & 909 & 0 . & .916 & & .913 \\
\hline Tests \# & Stat. & Prob. & i & Stat. & Prob. & Stat. & Prob. & $\begin{array}{l}\text { Stat. } \\
\end{array}$ & Prob. \\
\hline White & 0.517 & 0.987 & 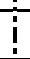 & 0.857 & 0.696 & 0.530 & 0.984 & 0.691 & 0.898 \\
\hline Ljung-Box & 14.155 & 0.291 & 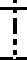 & 15.715 & 0.205 & \begin{tabular}{|l}
12.437 \\
\end{tabular} & 0.411 & 10.835 & 0.543 \\
\hline $\begin{array}{c}\text { Jarque - } \\
\text { Bera }\end{array}$ & 2.377 & 0.305 & i & 0.649 & 0.723 & 0.204 & 0.903 & 2.40 & 0.301 \\
\hline
\end{tabular}

Note: $*, * *$ and *** denote a 10\%, 5\% and 1\% level of significance respectively. For reasons of space the table reports only the significant spread-lag coefficients and does not report the estimated coefficients of the AR component, although overall significant. 
Table 7: Estimates of Probit model.

\begin{tabular}{ccccc}
\hline \hline & \multicolumn{4}{c}{$P\left(\right.$ recession $\left._{t}\right)=F\left(\alpha_{0}+\alpha_{1} s_{t-k}\right)$} \\
\cline { 2 - 5 } & $\mathbf{k}=\mathbf{3}$ & $\mathbf{k}=\mathbf{6}$ & $\mathbf{k = 1 2}$ & $\mathbf{k = 2 4}$ \\
\hline \hline$\alpha_{0}$ & $0.3193 * * *$ & $0.3228 * * *$ & $0.2379 * * *$ & 0.0747 \\
\hline$\alpha_{1}$ & $-0.2394 * * *$ & $-0.2124 * * *$ & -0.0335 & $-0.4172 * * *$ \\
\hline \hline RSS & 58.50485 & 58.25507 & 59.46097 & 49.99486 \\
\hline S.E. of regr. & 0.480879 & 0.482722 & 0.493652 & 0.464214 \\
\hline Log-lik. & -165.9178 & -164.7849 & -166.4095 & -143.5784 \\
\hline Restricted Log-lik & -172.9822 & -171.9949 & -170.4948 & -143.9348 \\
\hline McFadden $\mathbf{R}^{2}$ & 0.041545 & 0.033242 & 0.000892 & 0.102644 \\
\hline$\phi$ & 0.0550 & 0.0568 & 0.0331 & 0.0030 \\
\hline \hline
\end{tabular}

Notes: McFadden $R^{2}$ is computed as $1-\left(\frac{\log \left(L_{u}\right)}{\log \left(L_{c}\right)}\right)$, where $\log \left(L_{u}\right)$ and $\log \left(L_{c}\right)$ are respectively the unconstrained and constrained log-likelihood of the model, the latter being obtained when all the slope coefficients are constrained to zero. $\phi$ is

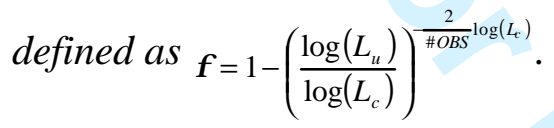

Table 8: Estimates of Probit model

\begin{tabular}{ccccc}
\hline \hline & \multicolumn{4}{c}{$P\left(\right.$ recession $\left._{t}\right)=F\left(\alpha_{0}+\alpha_{1} s_{t-k}+\alpha_{2} X_{t-k}\right)$} \\
\cline { 2 - 5 } & $\mathbf{k}=\mathbf{3}$ & $\mathbf{k}=\mathbf{6}$ & $\mathbf{k}=\mathbf{1 2}$ & $\mathbf{k = 2 4}$ \\
\hline \hline$\alpha_{0}$ & -1.0956 & -0.7210 & 0.6297 & 1.3987 \\
\hline$\alpha_{1}$ & $-0.3130^{* * *}$ & $-0.2652^{* * *}$ & -0.0154 & $-0.4842^{* * *}$ \\
\hline$\alpha_{2}$ & 0.0151 & 0.0111 & -0.0042 & -0.0142 \\
\hline \hline RSS & 58.21912 & 58.10119 & 59.43850 & 49.75950 \\
\hline S.E. of regr. & 0.480654 & 0.483051 & 0.494573 & 0.464122 \\
\hline Log-lik. & -165.1964 & -164.3997 & -166.3543 & -142.9602 \\
\hline Restricted Log-lik & -172.9822 & -171.9949 & -170.4948 & -143.9348 \\
\hline McFadden $\mathbf{R}^{2}$ & 0.045713 & 0.035502 & 0.001223 & 0.106507 \\
\hline$\phi$ & 0.0606 & 0.0598 & 0.0335 & 0.0083 \\
\hline \hline
\end{tabular}

Notes: as in Table 7. 
Table 9: In-sample forecasts: Hits and False Alarm.

\begin{tabular}{ccccc|cccc}
\hline \hline \multirow{2}{*}{ Model } & \multicolumn{4}{c}{$P($ recession $)=F\left(\alpha_{0}+\alpha_{1} s_{t-k}\right)$} & \multicolumn{3}{c}{$P($ recession $)=F\left(\alpha_{0}+\alpha_{2} L I_{t-k}\right)$} \\
\cline { 2 - 9 } & $\mathbf{k}=\mathbf{3}$ & $\mathbf{k}=\mathbf{6}$ & $\mathbf{k}=\mathbf{1 2}$ & $\mathbf{k}=\mathbf{2 4}$ & $\mathbf{k}=\mathbf{3}$ & $\mathbf{k}=\mathbf{6}$ & $\mathbf{k = 1 2}$ & $\mathbf{k}=\mathbf{2 4}$ \\
\hline \hline \# Obs. & 255 & 252 & 246 & 234 & 255 & 252 & 246 & 234 \\
\hline Hits & $105 / 149$ & $115 / 149$ & $145 / 145$ & $88 / 133$ & $95 / 149$ & $103 / 149$ & $145 / 145$ & $91 / 133$ \\
\hline $\boldsymbol{\%}$ & $\mathbf{7 0 \%}$ & $\mathbf{7 7 \%}$ & $\mathbf{1 0 0 \%}$ & $\mathbf{6 6 \%}$ & $\mathbf{6 4 \%}$ & $\mathbf{6 9 \%}$ & $\mathbf{1 0 0 \%}$ & $\mathbf{6 8 \%}$ \\
\hline False Alarms & $51 / 106$ & $53 / 103$ & $101 / 101$ & $38 / 100$ & $69 / 106$ & $68 / 103$ & $101 / 101$ & $40 / 100$ \\
\hline $\boldsymbol{\%}$ & $\mathbf{4 8 \%}$ & $\mathbf{5 1 \%}$ & $\mathbf{1 0 0 \%}$ & $\mathbf{3 8 \%}$ & $\mathbf{6 5 \%}$ & $\mathbf{6 6 \%}$ & $\mathbf{1 0 0 \%}$ & $\mathbf{4 0 \%}$ \\
\hline \hline
\end{tabular}

Table 10: Measures of out-of-sample accuracy of the two models.

\begin{tabular}{ccccc|cccc}
\hline \hline Model & \multicolumn{2}{c|}{$P($ recession $)=F\left(\alpha_{0}+\alpha_{1} s_{t-k}\right)$} & & \multicolumn{4}{|c}{$P($ recession $)=F\left(\alpha_{0}+\alpha_{2} L I_{t-k}\right)$} \\
\hline $\begin{array}{c}\text { Accuracy } \\
\text { Measure }\end{array}$ & $\mathbf{k}=\mathbf{3}$ & $\mathbf{k}=\mathbf{6}$ & $\mathbf{k}=\mathbf{1 2}$ & $\mathbf{k}=\mathbf{2 4}$ & $\mathbf{k}=\mathbf{3}$ & $\mathbf{k}=\mathbf{6}$ & $\mathbf{k}=\mathbf{1 2}$ & $\mathbf{k = 2 4}$ \\
\hline \hline QPS & 0.4760 & 0.4713 & 0.4863 & 0.4444 & 0.9530 & 0.9872 & 0.8127 & 0.5173 \\
\hline LPS & 0.6682 & 0.6639 & 0.6794 & 0.6499 & 1.4006 & 1.5135 & 1.0874 & 0.7378 \\
\hline KS & 0.0789 & 0.1316 & 0.0690 & 0.1633 & 0.0000 & 0.0000 & 0.0000 & 0.0204 \\
\hline \hline
\end{tabular}

Table 11: ISAE and ECRI business cycle chronology
ISAE
ECRI

\begin{tabular}{lccc}
\hline \multicolumn{1}{c}{ Peak } & Trough & Peak & Trough \\
\hline March 1980 & March 1983 & May 1980 & May 1983 \\
\hline March 1992 & July 1993 & February 1992 & October 1993 \\
\hline November 1995 & November 1996 & -- & -- \\
\hline December 2000 & -- & -- & --
\end{tabular}

Source: ISAE upon request from http://www.isae.it/, ECRI www.businesscycle.com

Table 12: In-sample forecasts performances: chronologies at compare.

\begin{tabular}{|c|c|c|c|c|c|c|c|c|c|}
\hline & & \multicolumn{4}{|c|}{$P($ recession $)=F\left(\alpha_{0}+\alpha_{1} s_{t-k}\right)$} & \multicolumn{4}{|c|}{$P($ recession $)=F\left(\alpha_{0}+\alpha_{2} L I_{t-k}\right)$} \\
\hline & & $k=3$ & $k=6$ & $\mathrm{k}=12$ & $k=24$ & $k=3$ & $k=6$ & $\mathrm{k}=12$ & $k=24$ \\
\hline \multirow{3}{*}{$\boldsymbol{H}$} & OECD & 70 & 77 & 100 & 66 & 64 & 699 & 100 & $\bar{~} 68$ \\
\hline & $I S A E$ & 48 & 42 & 65 & 69 & 2 & 0 & 49 & 63 \\
\hline & $E C R I$ & 10 & 10 & 5 & 0 & 0 & 0 & 0 & 0 \\
\hline \multirow{3}{*}{$F$} & OECD & 48 & 51 & 100 & 38 & 65 & 66 & 100 & 40 \\
\hline & $I S A E$ & 5 & 4 & 10 & 10 & 6 & 11 & 18 & 20 \\
\hline & $E C R I$ & 1 & 1 & 1 & 0 & 0 & 0 & 0 & 0 \\
\hline
\end{tabular}


Table 13: Out-of-sample accuracy: models and chronologies at compare.

\begin{tabular}{|c|c|c|c|c|c|c|c|c|c|}
\hline \multirow{2}{*}{$\begin{array}{c}\text { Accuracy } \\
\text { Measure }\end{array}$} & \multirow{2}{*}{ Chronology } & \multicolumn{4}{|c|}{$P($ recession $)=F\left(\alpha_{0}+\alpha_{1} s_{t-k}\right)$} & \multicolumn{4}{|c|}{$P($ recession $)=F\left(\alpha_{0}+\alpha_{2} L I_{t-k}\right)$} \\
\hline & & $k=3$ & $k=6$ & $k=12$ & $\mathrm{k}=24$ & $k=3$ & $k=6$ & $\mathrm{k}=12$ & $k=24$ \\
\hline \multirow{3}{*}{$O E C D$} & 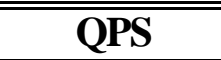 & 0.4760 & 0.4713 & 0.4863 & 0.4444 & 0.9530 & 0.9872 & 0.8127 & 0.5173 \\
\hline & LPS & 0.6682 & 0.6639 & 0.6794 & 0.6499 & 1.4006 & 1.5135 & 1.0874 & 0.7378 \\
\hline & KS & 0.0789 & 0.1316 & 0.0690 & 0.1633 & 0.0000 & 0.0000 & 0.0000 & 0.0204 \\
\hline \multirow{3}{*}{$I S A E$} & QPS & 0.8482 & 0.6934 & 0.5108 & 0.5194 & 1.0038 & 1.0123 & 0.8304 & 0.3278 \\
\hline & LPS & 1.2377 & 0.9285 & 0.7204 & 0.7178 & 2.2098 & 2.3906 & 1.1914 & 0.7462 \\
\hline & KS & 0.0000 & 0.0000 & 0.0833 & 0.1218 & 0.0000 & 0.0000 & 0.0000 & 0.5154 \\
\hline \multirow{3}{*}{$E C R I$} & 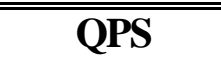 & 0.0427 & 0.1129 & 0.7807 & 1.4888 & 0.0076 & 0.0069 & 0.0147 & 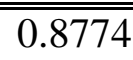 \\
\hline & LPS & 0.1579 & 0.2708 & 0.9937 & 2.5705 & 0.0538 & 0.0496 & 0.0837 & 1.3895 \\
\hline & $\mathbf{K S}$ & - & - & - & - & - & - & - & - \\
\hline
\end{tabular}

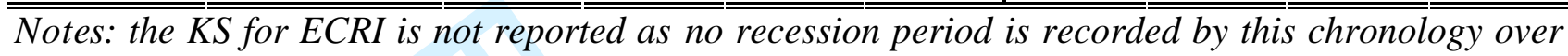
the out-of-sample period 1995 - 2005.

Table 14: A comparison with the literature

\begin{tabular}{cccccc}
\hline \hline Authors & $\begin{array}{c}\text { Dataset } \\
\text { (period and frequency) }\end{array}$ & Model & Chronology* & $\begin{array}{c}\text { Forecast } \\
\text { horizon }\end{array}$ \\
\hline $\begin{array}{c}\text { Estrella and } \\
\text { Mishkin (1997) }\end{array}$ & $1973-1994$ & Quarterly & Probit & CCIBCR & 1 and 2 years \\
\hline Moneta (2003) & $1971-2002$ & Quarterly & Probit & ECRI & 3 quarters \\
\hline $\begin{array}{c}\text { Sensier et al. } \\
(2004)\end{array}$ & $1970-2001$ & Monthly & Logit & ECRI & 1 quarter \\
\hline $\begin{array}{c}\text { Marotta et al. } \\
(2006)\end{array}$ & $1970-2002$ & Quarterly & Probit & ISAE and ECRI & 4 quarters \\
\hline This study & $1983-2005$ & Monthly & Probit & OECD & 2 years \\
\hline \hline
\end{tabular}

Notes: CCIBCR stands for Columbia Centre for International Business Cycle Research, ECRI for Economic Cycle Research Institute and ISAE for Istituto di Studi e Analisi Economica. 
Figure 1: True recession against estimated recession probabilities

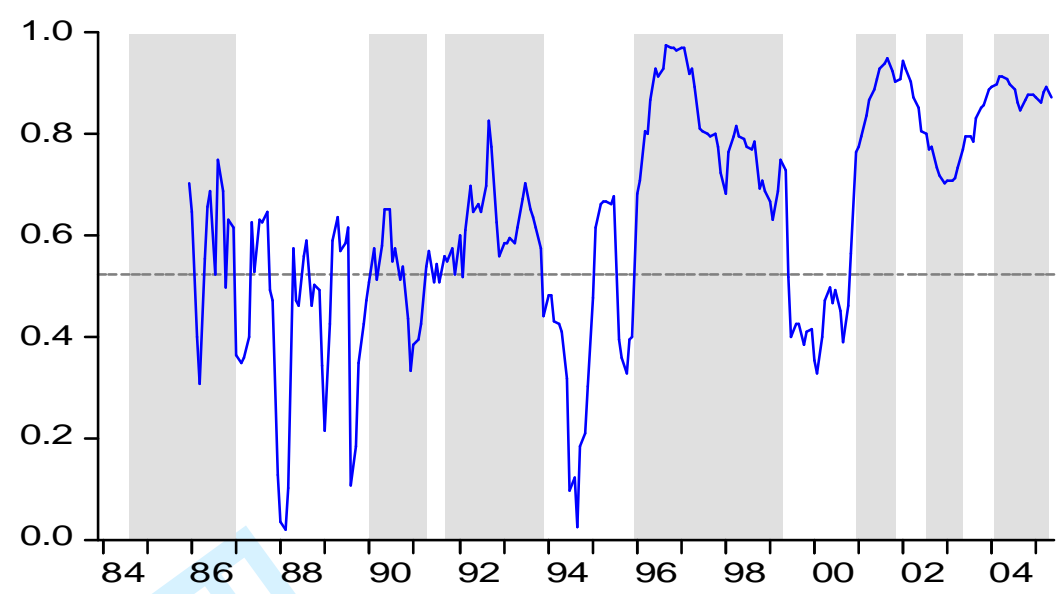

The shaded areas represent actual recessions as from the OECD chronology. The dotted line indicates the sample proportion (0.5231) while solid line represents the recession probabilities estimated using the two-years earlier spread. 


\section{Reply to Referee 1}

The Referee makes three main comments and five minor observations which we have found extremely useful in the revision of the paper. In what follows we describe in detail how we have taken all of them into account in the revised version of the paper.

To better illustrate the revisions made, we first report in italics the observations of the Referee and then we explain the work done stressing in bold at which point of the revised paper the changes required by the Referee have been made.

\section{MAIN COMMENTS}

1) The author performs his analysis using the OECD chronology for the period 1983-2005 and then he compares the results with other works, using different methodologies, another dating of the business cycle and other time intervals. In the abstract he states that recession forecasts are generally better than those obtained in the literature with other chronologies. In this case I expect a comparison with respect to the other chronologies using the same method and the same time span. I would like to see the results obtained with models (8) and (10) using the ISAE and ECRI dating.

According to the Referee's suggestion we have performed a comparison between the forecasts obtained under the ECRI and the ISAE chronologies with the model including the spread only former model (8), current model (10) - and the "benchmark" model including the OECD Composite Leading Indicator (LI) - i.e. former model (10), current model (12).

Specifically, we compare both in- and out-of-sample forecast performances of current models (10) and (12) under the chronology used in this study, i.e. the OECD one, with those obtained adopting ISAE and ECRI ones. This has entailed the addition of a few lines explaining this additional exercise at the end of Section 3.2, page 10 (referring to the methodology taken), of Tables 12 and 13, reporting the accuracy measures of respectively in- and out-of-sample forecasts performances at the end of Section 5, page 16-17, as well as a sum up on the results obtained in the Conclusions.

2) The second main comment of the Referee concerns the threshold model and basically consists of two sub-points.

The first one states "The main reason why the author uses a STR model is to verify the presence of nonlinearities and regimes in the economic growth rates. In addition, he uses the LST test to 
determine the delay parameter $d$. But the LST test can be used to very the hypothesis of linearity against nonlinearity, so that it can support the statement at the end of section 3.2".

In the previous version the description of the steps taken in this first part of the analysis was not clearly spelled out. In order to answer the Referee's comment we have slightly extended the beginning of Section 3.1 by describing the steps taken to perform the analysis based on the LSTR model: i.e. first, the linear specification and, then, the main steps of the LST test, run primarily to test for the presence of nonlinearities in such a model and then to determine the delay parameter $d$. The Section then concludes illustrating how we choose the best specification for the transition function $G$ between the logistic and exponential specification.

Revising this part of the analysis has required the inclusion of three additional equations and two additional tables (and hence the re-numbering of all the others reported in the remainder of the paper). The new equations, all reported at the beginning of Section 3.1, are: equation (1), page 5, describing the linear model specification; equation (2), page 6, describing the "auxiliary regression" on which LST test is based; and equation (3), page 6, describing the joint-significance hypothesis which basically represents the LST test. The new Tables are reported at the beginning of Section 4.1, page 11, and concern the grid search for the delay parameter $d$ (Table 2) and the results for the LST nonlinearity test (Table 3). Note that in the revised version of the paper the Appendix has been eliminated, as all the content (i.e. the determination of the delay parameter $\mathrm{d}$ by means of the LST test) is now completely included in the text.

The second sub-point states "Furthermore, I have some doubts about the correct specification of the LSTR model,; from table 4 (now Table 6) the presence of autocorrelation is clear. I think that it is necessary to add some AR component in the equation (1') (now equation (4'))".

In case of serially correlated residuals two are the possible ways to follow, i.e. re-estimating the model by imposing the Newey-West standard errors, which are consistent in presence of both heteroskedasticity and autocorrelation of the residuals, or including into the model AR components. According with the Referee's suggestion, we opt for the second way and include $j$ autoregressive components, whereby $j$ is set to 12 in the light of the monthly frequency of the data. The new specification of the LSTR model estimated is represented by equation (4'), page 12. In fact this choice completely eliminates any evidence of serial correlation in the residuals, although originates a problem of residual heteroskedasticity, which we tackle by imposing the White Heteroskedasticity consistent sandard errors when estimating the model. The new results, although not explicitly reported in a Table, are summed up in Section 4.1, page 13. In fact, despite the need for a nonlinear specification is proved, the evidence is not quite consistent with the theory across all forecast 
horizons. This may be due to the period considered, which specifically for the Italian case includes major macroeconomic events, such as the Italian Lira devaluation at the end of 1992 and the drop out from SME. We have thus re-estimated model (4') over a subsequent, less turbulent period spanning over Jan 1993 - Jul 2005. Results are reported in Table 6, page 13, commented thereafter at page 13-14 and summarized in the Conclusions.

3) I do not understand why the author compares the predictive performance of model (9) with that of model (10). They show that the coefficient of the variable LI is not significant and that model (8) is better than model (9). So why not compare directly model (8) and model (10)? I do not think that the two models have to be nested to perform this kind of comparison.

Essentially the Referee suggests to directly compare the forecast performances of probit model (10) (previous model (8), including the term spread only) with the benchmark model (12) (previous model (10), including the OECD Composite Leading Indicator). In the revision we adhere to the Referee's suggestion as follows.

We modify the sentence in Section 3.2, page 8, as follows: "To this end, forecast performances of model (10) can be compared with those of a benchmark model including the OECD composite Leading Indicator (LI) only".

Accordingly, we also modify the sentence at the beginning of Section 5, page 16, as follows: "More precisely, in- and out-of-sample forecasts of the model (10) including the term spread are compared with those of the benchmark model (12) including the OECD composite Leading Indicator (LI)".

The results of these comparisons are reported in Table 9, page 15, for the in-sample forecast performances and in Table 10, page 16 for the out-of-sample ones and the relative comments are reported thereafter at pages 16-17. Comments remain practically unchanged given consistency with previous results.

\section{MINOR REMARKS}

a) I think that more references are needed in some point of the paper. For example, in the introduction it is stated that the term spread is a largely accepted indicator of market expectations about future economic performances, but not references are quoted.

Hence, we add at the beginning of the Introduction, page 1 references to some among the most well known papers on the informative and predictive content of the TSIR about future economic performances, both in terms of growth rates and recession probabilities. Note that this has allowed the citation of a very recent study which has accordingly added into the References, namely: 
Ang, A., Piazzesi, M. and Wei, M. (2006) What does the yield curve tell us about GDP growth?, Journal of Econometrics, 131, 359-403.

The LSTR models are well known in the econometric literature, but it will be better to refer to the works of Terasvirta.

To answer the Referee's comment, at page 4 (and accordingly in the References) we refer to some seminal works on smooth transition models by Terasvirta, namely:

Terasvirta, T. and Anderson, H. M. (1992) Characterizing Nonlinearities in Business Cycles Using Smooth Transition Autoregressive Models, Journal of Applied Econometrics, 7,S119-S136.

Terasvirta, T. (1995) Modelling Nonlinearity in U.S. Gross National Product 18891987, Empirical Economics, 20, 577-97.

The typical alternative to the threshold models to capture the presence of regimes is constituted by the Markov Switching models (Hamilton, Econometrica 1989): are there not works in the framework faced in this paper? (For example Vazquez- Studies in Nonlinear Dynamics \& Econometrics, 2004)

To account for the Referee suggestions, we add a short paragraph at the beginning of Section 2, pages 3 and 4 in which we briefly review a couple among the most recent studies that model the nonlinearities of the relationship between term spread and economic growth in a Markov-Switching framework, namely:

Artis, M., Krolzig, H. M. and Toro, J. (2004) The European business cycle, Oxford Economic Papers, 56, 1-44.

Korenok, O., Mizrach, B. and Radchenko, S. (2004) The Microeconomics of Macroeconomic Asymmetries: Sectoral Driving Forces and Firm Level Characteristics, Rutgers University Economics Department Working Paper, 5, 1-20.

We also refer to another study suggested by the Referee in which the same Markov-Switching framework is used with different aim (i.e. investigating the relationship between the terms spread and the short rate changes rather than output growth rates), namely:

Vázquez J. (2004) Switching Regimes in the Term Structure of Interest Rates during U.S. Post-War: A Case for the Lucas Proof Equilibrium?, Studies in Nonlinear Dynamics \& Econometrics, 8, 1122-1122.

and as an example of different application we also cite 
Kim, C. and Nelson, C. R. (1999) Has the U.S. Economy Become More Stable? A Bayesian Approach Based on a Markov-Switching Model of the Business Cycle, Review of Economics and Statistics, 81, 608-16.

b) Page 7-Last row: the symbol of the error term is not the same of equation (7)

c) Equation (1) is present in section 3 and in section 4.1; I do not think that it is necessary to repeat it

d) In note 10 substitute "A investigation" with "An investigation"

e) Page 8, after equation (9): substitute "a series of-additional explanatory variable " with "a vector of-additional explanatory variable $(s)$ "

According to the last three minor remarks of the Referee, we correct the symbol for the error term of the auxiliary regression in the line under equation (2) (former equation (7)) at page 6, we correct the typing error in footnote 12 (former footnote 10) at page 11 and we substitute "a series of additional explanatory variables" with "a vector of additional explanatory variable(s)" in Section 3.2 after equation (11), page 9. 